\title{
Habitat characteristics with an. barbirostris larva density in Bulukumba
}

\author{
Iwan Suryadi $^{1}$
}

${ }^{l}$ Department Hygiene and Occupational Health and Safety, Sebelas Maret University

\begin{abstract}
Bulukumba is a malaria endemic area in South Sulawesi with malaria cases reported annually, An.barbirostris as a potential vector of malaria in the area. This study aims to analyze habitat characteristics with a density of An. barbirostris larvae The method used is an observational study with ecological survey design through the cross-sectional approach of samples in the form of Anopheles larvae habitat. Bivariate analysis shows physical, chemical, and biological environmental factors. water temperature significant to the density of larva An.barbirostris with p-value $=0,002$. Multivariate test using linear regression to know the most influential variables, it is known that the variables that have the most influence on the density of larvae An. barbirostris in endemic area Bulukumba is water temperature $\mathrm{p}=0,002$. Environmental factors such as salinity, aquatic plant, plants around, predators and crops along with water temperature are factors that support the density of An. barbirostris larvae Control can be done with environmental management, especially interventions on Anopheles sp larvae breeding habitat, by sowing predator fish seeds, habitat modification and manipulation. modification of anopheles habitat by covering habitats and carrying out development can reduce larval nutrition so as to reduce carbon in the soil which results in a decrease in larval density.
\end{abstract}

Keywords: Characteristics of Anopheles Habitat.

\section{BACKGROUND}

Malaria is one of the public health problems that can cause death especially in a high-risk group, and cause anemia and can decrease work productivity [1].

Indonesia in 2012 has a malaria mortality rate of 3.8 per 100,000 population, in 2012 the API of 1.69 and the 2013 API of 1.38. The Bulukumba Health Office records the number of malaria cases based on API values from 2009-2013. In 2009 the API in Bulukumba amounted to 4.29, the year 2010 API value to 5.3, In 2011 the value of API decreased to $0.29,2012$ and 2013 the value of API decreased by 0.13 . The decrease in API values is due to the presence of a global fund program in malaria control $[2,3]$.

Increased cases are caused by environmental changes One of the indirect impacts of environmental changes such as global warming is the change of mosquito-borne diseases, this is due to bionomic changes of mosquitoes such as changing the pattern of biting on Anopheles mosquitoes [4].

Research by Pfaehler et al showed that there was a significant relationship between carbon levels in the soil and larvae where high carbon content accelerated the growth of Anopheles larvae [5].

Environmental factors have a very important role in playing health such as Anopheles habitat. Research conducted by Rohani et al on mapping of mosquito breeding sites in endemic areas shows that there are more than $80 \%$ of habitat An. maculatus as a vector in the buffer of 100-400 m. This shows that the density of An. maculatus is very high in the endemic areas of malaria, as well as studies conducted by suwito et al on climate relations, the density of Anopheles $S p$ and the incidence of malaria shows that mosquito density is associated with increased incidence of malaria $(\mathrm{P}=0.021)$ [6,7].

Asniar et al about the entomology confirmation of malaria cases in Bulukumba, found the vector of Anopheles Sp. barbirostris Sulawesi Island prefers to suck human blood rather than animal blood with 6 species of Anopheles mosquitoes that have potential as a vector of transmission: An. barbirostris, An. vagus, An. subpictus, An. indefinitus, An. hircanus and An.kochi. An. barbirostris and An. subpictus becomes the most potential vector as a malaria transmitter. [8]

An. barbirostris is found in Rilau Ale with 3 tail, 0.3 density and habitat type in the form of river [9]. Studies of ecological characteristics and species composition of Anopheles are urgently needed to plan malaria control prorames. Bioecology An. Sundaicus in Ciamis became the basis of this study [10-11].

In nature An. barbirostris can inhabit larvae such as small ponds, swamps and rice fields. While in South Lampung found breeding ground An. barbirostris is found where An larvae breeds. barbirostris in paddy fields with moderate sunlight intensity, in Manggala, North Lampung found larvae An. barbirostris in paddy fields with a $\mathrm{pH}$ of water between 4.5-7.0. In Sikka Flores larvae. barbirstris found in flowing rivers and lagoons 
with a salt content of $0.2-10.4 \%$. In general the preferred habitat of larvae An. barbirostris of sunlit bodies of water, such as lagoons, ponds, slow running water, along river banks, and vegetable-grown rice fields and vegetation [12].

An. barbirostris found 2,104 heads in altitude areas in Sukabumi showed that spatial distribution of spatial can show the relation of environmental factor with abundance of Anopheles vector [13]. The purpose of this study was to analyze the habitat characteristics with the density of larvae An. barbirostris in Bulukumba .

\section{METHODS}

\subsection{Research Design}

The research design was observational with the design of ecological study through cross sectional approach that aims to find out the relationship between several research variables with environmental samples in the form of larval habitat.

\subsection{Population, Samples and Sample Criteria}

Population of all Anopheles mosquito breeding habitat in Bulukumba. While the research sample was breeding habitat of Anopheles mosquito in the data collected area. Sampling method was done by purposive sampling that was by done criteria in sample selection. Sample criteria are Selected samples are all samples found at the time of doing research that can be reached and can be done. The study sample was at a distance of 100-500 meters from the case house.

\subsection{Research Instruments}

The instruments used in this research are observation sheet, survey equipment and field laboratory equipment such as cuttings, pipettes, larval containers, net larvae, gutters, digital saltmeter, $\mathrm{pH}$ meters, label paper, Larva food and stationery.

\subsection{Data Collection Method}

\subsubsection{Survey of larvae}

Anopheles mosquito larvae surveys were observed for breeding habitats, population density, breeding characteristics in the study area. High density when there are at least 20 Anopheles larvae per cushion (dipper).. WHO standardized larvae survey method, with a volume of $350 \mathrm{ml}$, To determine the larval positive habitat:

1. Determination is done by scooping the body of water, where for the narrow body of water carried out as much as 10 times while for the water body wide is done more than 10 times.

2. If the larva contains larvae, then the larvae are observed by the species (Anopheles or not).

3. If the position of the larva parallel to the water surface, then the larvae are Anopheles
4. If the position of the larvae is not parallel to the surface of the captured water, then the larvae are not Anopheles.

5. The density is calculated by the formula of the density of the larvae.

$$
\text { density }=\frac{\text { number of caught }}{\text { captured number of larvae }}
$$

6. The identification is done by maintaining (rearing)

7. This activity is carried out by two people one part of the scooping one piece of record, this is done for ease.

8. larva identification was done in laboratory

\subsection{Data Processing and Analysis Data}

Analysis of observation result and entomology survey were done by univariate analysis in the form of tables and graphs with narration as explanation, bivariate analysis to know the influence and correlation between variables, and multivariate analysis to know the influence strength among variables.

\section{RESULTS}

\subsection{Distribution of Larva An Environmental Characteristics. Barbirostris}

Table 1. Shows the characteristics of larval habitat An. barbirostris based on the physical environment in Bulukumba where the dominant habitat in the rice field area is found in permanent type habitat with a silent water current. Preferred water temperatures are in the range between 20-300 C with habitats exposed to direct sunlight.

Table 2. Shows the characteristics of larvae habitat. An.barbirostris based on biological environment in Bulukumba where dominant habitat in rice field area, found in many kind of grass and paddy plants.

Table 3 shows the characteristics of larvae habitat $A n$. barbirostris based on chemical environment in Bulukumba where dominant habitat in rice field area, larvae An. barbirostris likes turbid water type with salinity $0-0.25 \%$ and $\mathrm{pH}$ between 6-9

Table 4. Indicates the correlation of habitat temperature with density of larvae An. barbirostris in Bulukumba with $p$ value $=0,002$ and $r$ value $=0,624$. It can be concluded that there is a significant influence of larvae water temperature habitat with larva density in An.barbirostris larvae breeding habitat and increasing temperature, the higher the density of An.barbirostris larva with strong correlation strength

Table 5 shows the effect of the presence of aquatic plants with the density of the larvae An. barbirostris in Bulukumba where there is significant influence with value of $\mathrm{p}$ value $=0,042$ and value $r=0,437$ shows strong correlation strength which mean existence of water plant at breeding habitat hence higher density of larvae An.barbirostris.

Table 6 shows the effect of salinity with the density of An larvae. barbirostris in Bulukumba where there is significant influence with value $p$ value $=0,039$ and value 
$\mathrm{r}=0,443$ indicates strong correlation strength which means higher habitat salinity level hence density higher also density of larvae An. barbirostris.

Table 1. Characteristics of physical enviroment habitat An. barbirostris.

\begin{tabular}{|l|c|}
\hline Characteristic Of Habitat & An. barbirostris \\
\hline Type of Habitats & \\
\hline Rice Fields & 11 \\
\hline River & 2 \\
\hline Kubangan & 2 \\
\hline swamp & 7 \\
\hline Habitat Properties & \\
\hline Permanent & 20 \\
\hline Not Permanent & 2 \\
\hline Speed of Water & 2 \\
\hline Not Flowing & 18 \\
\hline Flowing & 4 \\
\hline Water Temperature & \\
\hline $20^{\circ} \mathrm{C}-30^{\circ} \mathrm{C}$ & 14 \\
\hline$<20^{\circ} \mathrm{C}$ or $>30^{\circ} \mathrm{C}$ & 8 \\
\hline The Intensity of Sunlight & \\
\hline Open & 13 \\
\hline Half of open & 6 \\
\hline Close & \\
\hline
\end{tabular}

Table 2. Characteristics of biological enviroment habitat An. barbirostris

\begin{tabular}{|l|c|}
\hline Aquatic Plants & An. barbirostris \\
\hline Positive & 18 \\
\hline Negative & 4 \\
\hline Type of Aquatic Plants & \\
\hline Moss & 4 \\
\hline Water Hyacinth & 1 \\
\hline Grass & 11 \\
\hline Rice & 5 \\
\hline Negative & 1 \\
\hline Plants Around & \\
\hline Grass & 15 \\
\hline Shrubs & 3 \\
\hline Forest & 3 \\
\hline Negative & 1 \\
\hline
\end{tabular}

\begin{tabular}{|l|c|}
\hline Shade plants & 10 \\
\hline Negative & 3 \\
\hline \multicolumn{2}{|c|}{ Continues table 2} \\
\cline { 2 - 2 } Liuwueu
\end{tabular}

Table 3. Characteristics of chemical enviroment habitat An. barbirostris.

\begin{tabular}{|l|c|}
\hline $\mathbf{p H}$ & An. barbirostris \\
\hline $6-9$ & 22 \\
\hline Salinity & \\
\hline $0-0,25$ & 21 \\
\hline $0,26-0,5$ & 1 \\
\hline Turbidity & \\
\hline Clear & 6 \\
\hline Turbid & 16 \\
\hline
\end{tabular}

Tabel 4. The Influence of water temperature with density larva An barbirostris

\begin{tabular}{|c|c|c|}
\hline Variable & $p$ & $\mathrm{r}$ \\
\hline Water temperature & 0,002 & 0,624 \\
\hline density & 0,002 & 0,624 \\
\hline
\end{tabular}

Table 5. The influence of the existence of aquatic plants with density larva An. barbirostris

\begin{tabular}{|c|c|c|}
\hline Variable & $p$ & r \\
\hline Aquatic Plant & 0,042 & 0,437 \\
\hline density & 0,002 & 0,437 \\
\hline
\end{tabular}

Table 6. Effect of salinity with larva density An.barbirostris

\begin{tabular}{|c|c|c|}
\hline Variable & $p$ & $\mathrm{r}$ \\
\hline Salinity & 0,039 & 0,443 \\
\hline density & 0,039 & 0,443 \\
\hline
\end{tabular}




\subsection{Multivariate Analysis of Environmental Variables Against Larva Density}

Multivariate analysis is used to look at the most influential variable variables. The variables tested were water temperature, presence of aquatic plants and salinity for variables having a p value of 0.05 and surrounding plants as well as predators of larvae for variables having $\mathrm{p}>0.05$ but $<0.25$ as multicept test variables.

Table 7. Variable of influential variables on larva density An. Barbirostris

\begin{tabular}{|l|l|l|l|l|}
\hline Variable & $\mathrm{B}$ & $\begin{array}{l}\text { Koefisien } \\
\beta\end{array}$ & $p$ & $R^{2}$ \\
\hline $\begin{array}{l}\text { Water } \\
\text { temperature } \\
\text { (constanta) }\end{array}$ & 0,500 & 0,624 & 0,002 & 0,358 \\
\hline Aquatic plant & & & 0,886 & \\
\hline Salinity & & & 0,960 & \\
\hline
\end{tabular}

Table 7 results of analysis using multivariate regression test of liinier showed that water temperature is the most influential variable to density of larvae An. barbirostris where the water temperature can predict the density of the larvae with a correlation of 0.624 with the equation obtained by the density of the larvae An. barbirostris $=$ $0,500+0,500$ (water temperature).

\section{DISCUSSION}

This research was conducted in Bulukumba by taking 7 health centers in 6 sub $\mathrm{s}$ in Bulukumba namely Caile Public Health Center in Ujung Bulu Sub, Ujung Loe Public Health Center in Ujung Loe Sub, Bontobahari Health Center in Bontobahari Sub, Batang Health Center and Bontotiro Public Health Center in Bontotiro Sub, Bontobangun Health Center Sub Rilau Ale and Tanete Sub- in Bulukumpa .

Larvae An. barbirostris is found in Ujungbulu Sub, Ujungloe which is lowland and coastal as well as Bulukumpa and Rilau Ale which is highland area. If seen from the height of the area then Larva An. barbirostris can be found in lowland and upland areas.

Larvae An. barbirostris significant found in highland area that is in Bulukumpa and Rilau Ale and found in coastal area that is Sub Ujung Bulu and Ujung Loe. This is consistent with other studies stops et al that An. barbirostris has also been found to be associated with higher altitudes, rice fields, shallow water depths, higher water temperatures, higher $\mathrm{pH}$ and salinity, and average distances further from human habitation [14-15].

This study shows that An. barbirostris is a potential vector on the island of Sulawesi. An. barbirostris is commonly found in hilly areas and rice fields that are predominantly found in Tanete, Rilau Ale, Ujung Bulu and Ujung Loe Subs. This is relevant to the research conducted by Ndoen et al that the results of the study showed that An. barbirostris in the Central Java region is more common in areas in the highlands while in the East West, NTT is more common in coastal areas. Topography has a strong influence on the presence of Anopheles mosquitoes where topography shows that $A n$. barbirostris may be present at any altitude [16].

The study focused on being within a 500-meter radius of a malaria case house with considerably limited flight distance of mosquitoes over a range of 400 meters. Positive habitat is within 500 meters. So there is a potential risk of transmission. This study is relevant to the study by Ahmad et al that there is a correlation between the distance of the case house and the breeding habitat. In the study that the highest density at a distance of 200 meters.

Rohani Research shows the linkage between the distance of the house of malaria and Anopheles sp larvae breeding habitat as seen from the distance of the house of the case with the positive habitat, in that study it is explained that the distance of mosquito fly ranges from 100-400 meters. strong between the distance of breeding habitat and the transmission of malaria transmission [17].

Water temperature affects larval breeding. In general, Anopheles mosquito larvae prefer high temperatures when compared with the type of culicinae. That is why more Anopheles species encountered in the tropics. The time of hatching Anopheles mosquito eggs is greatly influenced by the water temperature at the breeding grounds. The higher the water temperature the hatching time is shorter. The water temperature has a correlation to the density of the An larvae. barbirostris in Sub Ujung Loe with average larvae An. barbirostris was found at qualified water temperature, multivariate analysis and analysis that water temperature had the strongest effect on density of An.barbirostris larvae in Kecamatan Ujung Loe compared with the variables. This is in line with research conducted by Christiansen et al, on the relationship of temperature to larval reproduction indicating that the optimal temperature for the development of larvae An. gambiae between 23-310C. Similarly, research by Rohani et al that on habitat characteristics and mapping An. maculatus in Malasyia showed water temperature in each of the studied habitats 21-310C [17-18].

Research on the correlation of water temperature with Anopheles larvae density is also in line with research conducted by Hanafi et al. In the study it was explained that at 20-30 0C temperatures found many Anopheles larvae in various types of breeding habitat [19-20].

Water plants in breeding habitats play a significant role in the presence of Anopheles larvae. This is because the aquatic plants can function as mosquito breeders on the surface of the water, this is in accordance with research conducted by [21] Algae and decaying water plants on the surface of the widespread water and get direct sunlight greatly affect the proliferation of larvae, this is due to microfauna and microflora as food larvae are gathered around the plants The existence of water plants such as algae and moss indicate habitat water conditions as a good breeding ground. The existence of algae as a refuge for larvae from predatory attacks This is in line with research conducted Santjaka (2013) that 
the existence of aquatic plants is a medium to avoid predatory attacks [22].

In general Anopheles mosquitoes favor habitats that have low salinity, but some Anopheles species such as An.subpictus can live in areas with high salinity such as ponds and coastal areas. This study is relevant to research conducted by Soelamani et al that there is a strong correlation between salinity and Anopheles larvae density. This is also consistent with research conducted by Seid Tiku Mareta that different salinity levels in different types of breeding habitat affect the density of An. subpictus larvae. [23-24]

Other variables that have significant but insignificant influence are predators and the presence of surrounding plants as shade plants. The density of mosquitoes is influenced by the presence of larvae-eating fish species, such as tin head fish, tilapia, goldfish and milkfish. The existence of this shade plant is associated with its function of blocking sunlight from entering the soil, thus the lighting will be low and the moisture will increase. This condition is the optimal condition for mosquitoes to rest after sucking blood while waiting for the process of egg maturation and then placed in the nearest habitat.

The description shows that Anopheles larvae control became the focus of this study. The control of larvae such as the maintenance of fish as a predator of larvae to be one way in control program and improving the implementation of entomology survey by forming larva monitoring groups in each village to conduct monitoring and mapping of habitats and cases on a regular basis.

\section{CONCLUSIONS AND RECOMMENDATIONS}

Characteristics of the physical environment of temperature becomes the most influential variable on larva density An.barbirostris. The distribution of Anopheles larvae found in this research is An.barbirostris, An.subpictus, An.vagus, An.hyrcanus and $A n$. indefinitus. modification of anopheles habitat such as puddles and non-productive habitats by covering habitats and carrying out development can reduce larval nutrition so as to reduce carbon in the soil which results in a decrease in larval density.

\section{REFERENCES}

1. F.J. Laihad Malaria Epidemiology Bulletin in Indonesia. Ministry of Health of the Republic of Indonesia, 1-10. (2011).

2. Health Profile of the Republic of Indonesia. Jakarta: Ministry of Health Republic of Indonesia.

3. Health Office Bulukumba. Malaria Report. Bulukumba: Bulukumba Health Office. DG of Disease Control and Environmental Health. (2014).
4. U. Fachmi Achmadi Dasar-Dasar Penyakit Berbasis Lingkungan. Rajagrafindo Persada: Jakarta. (2011).

5. O. Pfaehler, D.O. Oulo, L.C. Gouagna , J. Githure , and P.M. Guerin. J of Vctr Eclgy 31, 404 (2006).

6. R. Ahmad , W. NWM Ali, Z. M. Noor, Z. Ismail, A. A Hadi, M. N Ibrahim, L H Lim. Malaria J 10, 1 (2011).

7. Suwito, U. K. Hadi. S. H Sigit. \& S. Sukowati, J Entomol IndonI 7, 42-53. (2010).

8. Asniar, H. Ishak, I. Wahid. Unhas Repository, 1-8. (2012).

9. Yunicho. (Thesis). Makassar. (2014).

10. P. Dhewantara, W. Endang, P. Astuti, F. Yanuar Pradani. J o R \& D Center P2B2 41, 27-28 (2012).

11. H. Kassiri and Amani. H. Zjmrs J 14, 11-12 (2012).

12. I. R. F. Elyazar, M. E Sinka, P.W Gething, S. N. Tarmidzi, A. Surya. R. K. Winarno, J. Kevin Baird, S. I Hay, M. J Bangs. Adves is Prstolgy Elsvier 83, 186-189 (2013).

13. C. Stoops, A. S. Rusmiarto, D.Susapto, A. Munif, H Andris, K. A Barbara, S. Sukowati. J of Vetr Eclgy 34, 200-207 (2009).

14. C. Stoops, A. Y. R Gionar, Shinta, P. Sismadi. I. R.F. Elyazar, M. J Bangs, S. Sukowati. J o Mdcal Entmlgy 44, 1 (2008a).

15. C. Stoops A. Y. R Gionar, Shinta, P. Sismadi, A. Rahmat. I.R.F Elyazar, S. Sukowati. J o Vctr Eclgy 33, 36-38 (2008b).

16. E. Ndoen, C. Wild, P. Dale, N. Sipe, M. Dale. Malaria J 9, 4-9 (2010).

17. R. Ahmad, WMA. W. Najdah, I. Zamree, A.H Azhari. I. M Noor. H Rahimi and H.L Lee. J Trop Mdcl PH 41, 1-10 (2010).

18. C.C. Juct, P. E. Parham, A. Sadler, J. C koella, M. G. Basanez. J Prste \& Vctr 7, 1-10 (2014).

19. H. Bojd, A. A. H Vatandoost, M. A Oshaghi, Z. Charachy. A. A Haghdoost, M. M Sedaghat, F Abedi, M Soltani \& A. Raesi. J o Vctr Born Disease 49, 93-99 (2012).

20. H.Bojda, A. A. Vatandoosta, H. Oshaghia, M. A. Charrahyb, Z. Haghdoostc, A. A. Zamanid, G. F Abedi. M.M Sadaghat, M Soltani, M Shahi, A Raesi. Act Tropica Elsvr J 122, 132-137 (2012).

21. R. R. Rahman, H. Ishak, and E. Ibrahim, Repository of Unhas, 1-14. (2013).

22. Santjaka. Malaria Pendekatan Model Kausalitas. Nuha Medika: Jakarta. (2013).

23. S.T. Mareta, D. Yewhalaw, P. Boets, A. H. Ahmad, L. Duchateau, N. SpeyBroeck, S. V. W .Legesse, L. D. Meester, P.L.M Goethal. Journal Prsts \& Vctr 6, 1-6 (2013).

24. M. Ahmadi, H. Soleimani, A.A , H. Bojd, M. Zare, R. Saffare, A. R. Mojahedi, F. P. Garbandi. J of Pasific of Trop Med 7, 512-514 (2013). 